Article

\title{
Sustainable Business Model Based on Digital Twin Platform Network: The Inspiration from Haier's Case Study in China
}

\author{
Xiao Li*(D), Jiarou Cao, Zhenggang Liu $₫$ and Xinggang Luo \\ Management School, Hangzhou Dianzi University, Hangzhou 310018, China; caojiarou@hdu.edu.cn (J.C.); \\ liuzhenggang@hdu.edu.cn (Z.L.); xgluo@hdu.edu.cn (X.L.) \\ * Correspondence: lixiao@hdu.edu.cn; Tel.: +86-1306-795-0189
}

Received: 31 October 2019; Accepted: 23 January 2020; Published: 27 January 2020

\begin{abstract}
Sustainability and digitalization have become the main direction of transformation of enterprises. Building a digital twin platform network can provide enterprises with a comprehensive view of products, manufacture, supply chain, customer experience, and profitability, which is conducive to the construction of a sustainable business model. The purpose of this paper is to study how enterprises use digital twin platform networks to generate economic, social and environmental benefits in various dimensions and their coupling relationships. Based on the literature review, this paper constructs a five-dimensional framework of a sustainable business model, and analyses the coupling relationship between dimensions. Using Haier as a way to verify the five-dimensional framework, it explores the dynamic mechanism of the Haier digital twin platform network, constructs an integrated framework based on coupling perspective and compares it with other two home appliance enterprises. The study shows that, through the digital twin platform network, enterprises can remove the disadvantage of focusing on a single product life cycle, and form a comprehensive network, so as to promote overall sustainable upgrades. This paper draws generic strategies and digital transformation suggestions for enterprises to innovate the sustainable business model. The conclusion enriches the research on sustainable business models both theoretically and practically and provides a feasible reference for the transformation of enterprises in digital economy environment.
\end{abstract}

Keywords: digital twin platform network; sustainable business model; coupling relationship; transformation mechanism; Haier

\section{Introduction}

The pressure of economic, social and environmental sustainability is a major challenge that the whole of human society is facing, and thus sustainable development has become a prominent theme of human development. As the main participants in economy activities, enterprises occupy the majority of social resources, and therefore play an important role in shouldering the historical mission of realizing sustainable development, which can possibly be achieved by adopting sustainable business models [1,2]. A sustainable business model is economically, environmentally and socially sustainable [3]: it must help companies not only achieve fundamental reductions in energy and material consumption but also obtain financial and social benefits while providing the necessary products or services. It might have the additional benefit of a higher risk mitigation and resilience [4], yield additional diversification and value co-creation opportunities [5]. Numerous researchers and practitioners emphasize the significance of innovating sustainable business models [6,7]. However, most of the research about sustainable business models was carried out from the perspective of an individual product's life cycle [8] or sustainable dimensions. Little attention has been paid to 
co-creation and the relationship among these dimensions. Ceccagnoli et al. [9] proposed that, by joining in co-creation with stakeholders, enterprises can achieve significant benefits. From the perspective of customer value co-creation, Prahalad and others [10] suggest that enterprises can expand their interaction with customers to other aspects besides sales and service. Coupling between dimensions of the sustainable business model can help to expand value co-creation to more dimensions. In that case, the coupling of sustainable business model dimensions, and how to include more stakeholders in value co-creation, should be further studied.

With the explosive growth of data resources and the continuous innovation of digital technology, the digitization process in all fields of economy and society is accelerating, among which the deep integration of new generation information technology and the manufacturing industry, such as intelligent manufacturing (especially digital twin) is leading the transformation of the manufacturing model and cultivating the manufacturing industry for better sustainability. Parida et al. [11] suggest that digitalization, coupled with the implementation of business model innovation, can yield important economic, environmental and social benefits. Digital twin is an effective technology to fulfill the requirements of digitalization by reflecting the physical status of systems in a virtual space and performing intelligent decision-making with simulations [12,13]. The digital twin paradigm that aligns well with a lifecycle-centered perspective initiates new kinds of business model innovation. It can effectively connect the device layer and network layer. Integrating the fragmented digital information with platforms and then constructing the network between platforms can make the various digital twins correlate with and complement each other, and thus improve the efficiency and effectiveness of resource aggregation, dynamic allocation, etc. However, only a limited number of enterprises have already made rapid advances by developing structured digital strategies to obtain a competitive advantage $[14,15]$. Studying the sustainable business model (SBM) based on the digital twin platform network with coupling viewpoint has both theoretical value and practical value. The digital twin platform network can provide strong digital support and comprehensive visibility. It can achieve efficient internal and external communication and strengthen the coupling relationship between dimensions. As developing a digital twin network platform by focusing on coupling mechanism can result in better sustainability, how to use digital twin to develop a sustainable business model in the digital economy environment has been put on enterprises' agenda.

Combined with the above background, this paper focuses on how enterprises use the digital twin platform network to generate economic, social and environmental benefits in various dimensions of the sustainable business model, and the coupling relationship between them. Digital twin is a virtual mapping of real value links, and the construction of a digital twin platform network can form many coupling points. It can not only produce higher benefits among various dimensions of the sustainable business model, but also realize the coupling between dimensions through the integration of the platforms, so as to prompt more efficient information sharing and resource allocation. The aim of this paper is to explore this research gap empirically through a case study of Haier. To answer the "how-to" question, it adopts an exploratory case study method. The study is structured as follows. Section 2 presents the literature on sustainable business models and digital twin. Section 3 is about the specific content of the theoretical framework. The methods used to analyze the case studies are then detailed in Section 4, including an overview of Haier and case analysis based on the theoretical framework. In Section 5, the results, this paper puts forward an overall strategy and suggestions for other enterprises to refer to. To conclude, the managerial and academic implications, limitations of the study and future study indications are provided.

\section{Literature Review}

Sustainable business models are gradually forming a new trend in the research of business models [16,17]. The past two decades have seen increased interest in strategies for business sustainability in both academia and the business sector [18-20]. Integrating technology innovation with business model innovation is one main challenges in the creation of SBMs [1,21], and this technology innovation 
is presently focused on clean technology [22,23], and might need more focus on information and communications technology (ICT) in e-business [24,25] and advanced manufacturing technology (AMT) in manufacturing firms [26], especially for ICT in intelligent manufacturing (such as digital twin) in the era of the digital economy. The purpose of adopting digital technology in sustainable business model innovation is to use it as a strategic asset for competitive advantage and firm performance [27], and a tool for the systemic analysis, planning, and communication of the configuration and implementation of one or more organizational units [28]. In this section, Section 2.1 deals with the relationship between three benefits of sustainable business models; Section 2.2 is about ways to develop sustainable business models; Section 2.3 presents the literature about digital twin and the network.

\subsection{Sustainable Business Model Based on Triple Bottom Line Perspective}

According to previous research and the literature, the research on sustainable business models mainly focuses on the consideration of economic, social and environmental benefits [7,29]. Bansal and Roth [30] proposed that the three basic motivations for enterprises to pursue sustainability are: competitiveness, legitimacy and ecological responsibility. Stubbs and Cocklin [31] were the first scholars to explicitly propose the concept of the sustainable business model, which they called "Sustainability business models". They believe that core of this concept is sustainability, as it plays an integrated role in forming the mission and driving force of enterprises. It is a "sustainable embedded business mode" which transcends the economic dominance mode of traditional neo-classical economics. Sustainable business models should not only consider economic sustainability, but also focus on social and environmental sustainability. From the perspective of system theory, the sustainable business model can construct a triple bottom line approach to define corporate goals and measure performance, which includes a wide range of stakeholders, especially the environment and society [23]. Steve Evans et al. [1] comprehensively summarized the forms of the economic, environmental and social benefits included in sustainable business model. Economic benefits include profit and a return on investment; environmental benefits include unit energy consumption, and renewable resources use; social benefits include community development and labor standards. Qu et al. [32] emphasized the importance of green upgrading in the manufacturing industry. They combine multiple indicators to establish an environmental pollutant composite index and employ the EBM model (with labor, capitals and energy as inputs and the gross industrial output and the environmental pollutant composite index as outputs) to measure the green growth efficiency for manufacturing industries in China. Most of the environmental sustainability studies are conducted from the perspective of product life cycle, while the social sustainability studies are mainly based on the perspective of stakeholders. Im and Sun [33] proposed that key stakeholders include nonprofit social partners, world-wide charitable organizations and governments. There are two dimensions to measuring social benefits: one is the breadth of stakeholders involved, and the other is the depth of the stakeholders served.

Subsequent research mainly focused on the relationship between economic, social and environmental benefits. Boons and Lüdeke-Freund [34] define a sustainable business model as a business model that creates value by balancing economic, environmental and social benefits, improving equal relations among stakeholders and adopting a fair income model. Schaltegger et al. [35-37] emphasize the causal relationship between economic benefits and social or environmental benefits. Ekwueme et al. [38] and Hussain et al. [39] studied the relationship between corporate governance, performance and the sustainable development of the triple bottom line, and found that the value proposition of the sustainable business model can be summed up as three categories, namely economic, social, and environmental value. A business model for sustainability should have the characteristics of creating economic benefit through voluntary social or environmental behavior, rather than simply showing the coexistence of economic benefit and social or environmental behavior. Matos and Silvestre [40] quoted Boons and Lüdeke-Freund [34]'s definition, and further noted that a sustainable business model is about the balance between economic, ecological and social benefits, not any of the elements considered in isolation; the three elements are interdependent and interacting. 
Boons and Lüdeke-Freund [34] describes the sustainable business model as 'a business model that creates competitive advantage through superior customer value and contributes to a sustainable development of company and society. Building on Garetti and Taisch's [41] views on sustainable manufacturing, sustainable business models preserve the environment, while continuing to improve the quality of human life. Stubbs and Cocklin [31] assert that sustainable business models use both a systems and firm-level perspective, based on the triple bottom line approach to define the firm's purpose and measure performance. It includes a wide range of stakeholders [42] and considers the environment and society as stakeholders. A sustainable business model aligns the interests of all stakeholder groups, and explicitly considers the environment and society as key stakeholders.

Combining the above SBM concepts, and based on the definition of business model value, the sustainable business model is defined as a model for enterprises to create, transfer and acquire economic, social and environmental values sustainably. It can seek a balance among economic, social and environmental benefits, and obtain wider support by satisfying the demands of stakeholders, so as to promote the sustainable development of enterprises and ultimately promote overall economic, environmental and social sustainable development.

At present, there are many researches on the three benefits of the sustainable business model, but the current research on how to obtain profit and competitive advantage from the enterprise's environmental and social behavior is still unclear. Discussion of this conversion mechanism will be important content for future sustainable business model research. In addition, how to effectively evaluate economic value, social value and environmental value is also an important topic in this research field, which involves the redefinition of value proposition and reconstruction of evaluation method.

\subsection{Constructing Sustainable Business Model}

There are a lot of researches focusing on ways to acquire and develop sustainable business models. Schaltegger et al. [35] referred to them as "Business models for sustainability", and they are considered to be the "foundation of organizational model" that contributes to the sustainable development of the organization [31]. Sosna et al. [43] argue that if an enterprise can come up with a new mix of trading content, structure, and governance, while creating value for all stakeholders and gaining value for itself, it can be said that the enterprise has already formed a sustainable business model. Abdelkafi and Tauscher [44] point out that the core logic of the sustainable business model is to create an enhanced cycle of creating value for customers, gaining value for enterprises and putting value into the natural environment [23].

Boons and Lüdeke-Freund [34] defined SBM as "a business model that creates competitive advantages through exceptional customer value to enable sustainable development of enterprises and society". They drew on the view of business models as "market tools" and considered that business models as a medium to achieve sustainable innovation. Business models can provide a new perspective for sustainable innovation. They put forward four normative requirements of sustainable business models on the basis of reviewing the existing business model and sustainable innovation literature: 1 . value proposition-it provides measurable environmental and social values that are consistent with economic values; 2 . supply chain-it involves suppliers who are responsible not only for themselves but also for the stakeholders of the core enterprise, so enterprises do not transfer their own social and environmental burdens to suppliers. This requires enterprises to effectively integrate suppliers into sustainable supply chain management; 3 . Customer interface-customers should be encouraged to take on their own environmental responsibilities, and enterprises should not pass on social-environmental burdens to their customers; 4 . financial model—this reflects the proper distribution of economic costs and benefits among all stakeholders involved in the business model. It also explains the impact of the enterprise on the environment and society.

Based on the principle of triple bottom line, Joyce and Paquin [45] analyzed the sustainability of Nescafe's business model at three levels: economic, social and environmental. They propose a triple layered business model canvas for designing sustainable business models, integrating the three levels 
of economic, social, and environmental values into a holistic view of an enterprise's business model based on product lifecycle and stakeholder theory.

Based on the above literature review on the sustainable business model, we can see that the research on sustainable business models has achieved preliminary results. Many researches are based on the development tools and paradigms of sustainable business model. Scholars have different definitions of the elements of a sustainable business model, but most of them expand on and extend the definition of "value proposition, value creation and transmission, value acquisition" in the social and environmental dimensions. Secondly, the current research on sustainable business models mainly focuses on innovation path, individual product life cycle, dimensions and components, while the research on the correlation between dimensions is less. Sun and Zou [46] propose that knowledge integration across multiple product generations will benefit the innovation of enterprises. In that case, whether information integration across different life cycle links is conducive to the performance of enterprises still needs to be further studied.

At present, there are also some researches exploring the coupling relationship between dimensions from the perspective of the business model. Morris [47] and others put forward that the business model is the expression of how the variables in the strategy, structure and economy of the enterprises are related to each other to create sustainable competitive advantage in the defined market. Business model is not only a multi-element structure, but also needs consistency and coordination between elements. Giesen [48] also believes that the key to the successful innovation of the business model lies in the balance and strong matching between internal and external elements, as well as continuous guidance of internal and external elements. Sorescu [49] emphasizes that, as the organizational logic of creating value for customers and distributing value to enterprises and their partners, the business model has a clear and interdependent structure, which is represented by revenue model, cost structure, resource and value proposition. This fundamentally reflects how enterprises make these activities match and adapt to the environment. A successful business model's design and innovation needs to clarify the value proposition, determine the market segment, define the structure used to create and distribute products or services, explain the financial model, and fully explain the internal logic relationship and structure of the elements. However, most of the studies are carried out at the economic level. It is necessary to expand the coupling of business model dimensions to the social and environmental level, that is, to study the coupling relationship of sustainable business model dimensions.

Furthermore, in recent years, the digital transformation of manufacturing $[50,51]$ is finding a growing interest both at practitioner and academic levels in the sustainable business model field. They can create value by connecting different players and machines in a new "digital thread" across the value chain, relying on the availability of an unprecedented, huge amount of data to address manufacturers' key business drivers. Bonilla et al. [52] outlined four different scenarios to evaluate the impacts of the Industry 4.0 production context and its underpinning technologies on environmental sustainability aspects. Antoio et al. [53], based on previous literature analysis and taking sustainability and manufacturing as the main object, concluded that digitalization is a powerful tool for enterprises to achieve sustainable manufacturing and innovate the sustainable business model. Marco Savastano [54] proposed that digital technology and digital manufacturing have significant advantages in improving production efficiency, customized production, flexibility and sustainability. Enterprises need to achieve a good understanding of the latest digital platforms and applications across the manufacturing value chain and run specific simulations to verify the real, achievable benefits.

Although the digital network, as a key feature of intelligent manufacturing, has become the main development direction of enterprises, there is a research gap regarding how to implement transformation through intelligent manufacturing, and how to implement sustainable upgrades through industrialization and informatization.

Martin Geissdoerfer [7] and others proposed that how to develop the sustainable business model from the perspective of resource and technological innovation is one of the challenges facing the current research. Some scholars have begun to study the application of digital technology in sustainable 
business model innovation, but there are still few studies on how to use digital technology to achieve their own sustainable transformation and upgrade. In the future, we need more in-depth research on the relationship between the elements of the sustainable business model, the three benefit transformation mechanisms, and the internal mechanisms of enterprises using their own capabilities to combine new technology with business model innovation.

\subsection{Digital Twin and Network}

With the development of industry 4.0, intelligent manufacturing and other technologies and development strategies, digital twin has gradually become a basic element of intelligent manufacturing, and has been widely implemented. There are many different definitions and understandings of digital twin in industry and academia, but fundamentally, digital twin is the digital representation of physical items or assembly through integrated simulations and service data [12,13]. The concept of digital twin can be traced back to the product lifecycle management (PLM) course taught by Michael Grievs in 2003 [13]. The initial digital twin consists of three parts: real space, virtual space and the data flow connection between them. Digital twin holds information from multiple sources across the product lifecycle, which is continuously updated and visualized in a variety of ways to predict current and future conditions [54]. It runs through different stages of product life cycle, which coincides with the concept of PLM. It can be said that the development of digital twin technology has really extended the capability and concept of PLM from the design stage to the whole life cycle.

In recent years, the concept and application of digital twin has been gradually reflected in intelligent devices and intelligent factories. Tao et al. [55] proposed that digital twin is an integral part of the product life cycle (PLM), which uses physical data, virtual data and interactive data to map the product in real time. The digital twin model of a product can reduce the time consumed in the process of design and production, meet the needs of customer customization, and manage the whole product life cycle to improve the response speed to market demand. Soderberg et al. [56] use the digital twin of a product assembly process to realize the rapid transformation from mass production to personalized production. Digital twin can collect, record, accumulate and process all data from product design to recycling, so it is not only conducive to the design, manufacture, use and maintenance of products, but also to the development of next generation products [57]. Liu et al. [58] described it as one of the strategic directions for manufacturing enterprises to progress. Lim and others [59] suggest that digital twin can be used from the perspective of business model innovation. When incorporated with big data, it will result in better decision-making support.

Digital twin can effectively connect the device layer and network layer, and help to collect, transfer and integrate the fragmented knowledge in the industrial system into the platform [60]. Studies by Cenamor et al. [61] and Eloranta et al. [62,63] recognize the importance of the platform in undertaking digital transformation in the pursuit of strategic opportunities; they propose that the use of a platform to share information can achieve a higher degree of customization and operational efficiency through front-end and back-end integration. The construction of a network between platforms makes the various digital twins begin to correlate and complement each other in equipment asset management, product lifecycle management and manufacturing process management. Using the advantages of the platform, such as resource aggregation, dynamic allocation, supply and demand docking, to integrate all kinds of resources, can make digital twin play a more effective role in all value links. It forms many coupling points between operation and sustainable business models of enterprise. Mont [64] argues that a systematic approach based on the product life cycle provides companies with a competitive advantage by allocating resources more efficiently to where they are most needed $[65,66]$. In that case, developing a digital twin network platform by focusing on coupling mechanisms can result in better sustainability.

The digital twin platform network defined in this paper refers to the network formed by the mutual connection between the digital twin platforms of enterprises. Enterprises have established a number of independent platforms for different departments and value links. Through the platform 
network, these platforms communicate and share information. It is precisely because of the composition of the network between platforms that enterprises can break the independence of each department and realize the coupling between dimensions. The complementary platform network formed by products, assets, facilities and factories digital twin, which covers the entire enterprise, will provide information about process, implementation and performance, and achieve data synchronization. As a digital twin platform network can provide strong digital support and comprehensive visibility, it can achieve efficient internal and external communication and strengthen the coupling relationship between dimensions. With this network, enterprises can adopt an intuitive way to make decisions and allocate resources more efficiently.

\section{Theoretical Framework}

Based on the four elements of the sustainable business model proposed by Boons and Lüdeke-Freund [34], this paper combines the value proposition, value creation and delivery, and value acquisition proposed by Teece [67] and Richardson [68]. This paper proposes a five-dimensional business model framework.

\subsection{Structure of Sustainable Business Model Framework}

The framework of sustainable business model in this paper consists of five dimensions with a coupling relationship, namely value proposition, value creation, value network, financial model and customer interface, as shown in Figure 1.

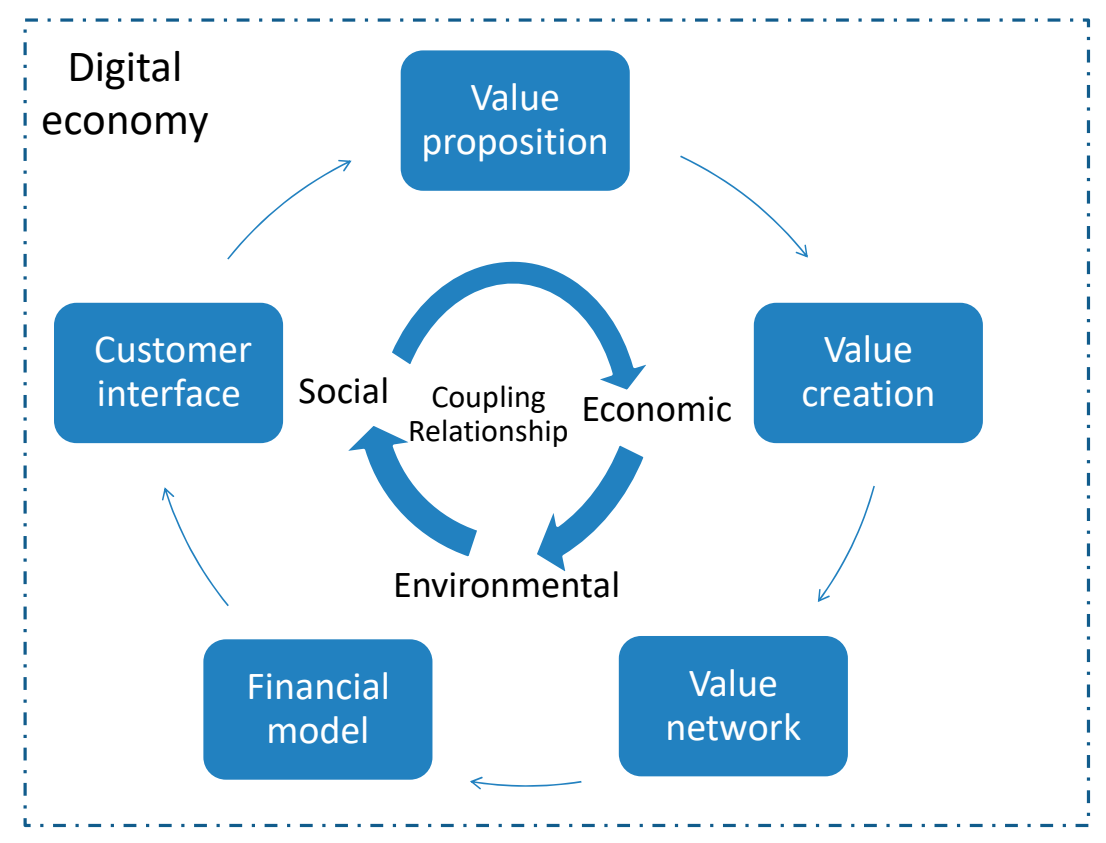

Figure 1. Dimensions of the sustainable business model.

Value proposition usually refers to why customers recognize and are willing to buy the products or services of an enterprise, that is, what value the products or services of an enterprise can bring to customers. To some extent, value proposition determines the positioning and integration of the strategic direction, operation structure and overall business process of the enterprise. Value proposition in a business model includes two meanings: what kind of products or services an enterprise can provide and who the target customer of the enterprise is. The sustainable business model, on the other hand, includes more stakeholders into the scope of value proposition, meaning the environmental and social aspects, that is, what positive impacts an enterprise's products or services can have on the environment or society. The following two questions need to be clarified: what value the products and services of the enterprise can bring to the environment and society, and what kind of relationship the 
enterprise has established with the stakeholders at the environmental and social levels. Sustainable business models provide measurable environmental and social values which are consistent with economic values. They are a reflection of the dialogue between business and society in balancing economic, environmental and social needs.

Value creation refers to a series of production activities carried out by enterprises, using their own infrastructure to produce and provide the products or services required by customers; that is, the process of effectively creating value proposition. Value creation, as the core link supporting the operation of enterprises, involves a large number of human and material resources. It is bound to play an important role in the environment and the social benefits of enterprises. Therefore, the sustainable upgrading of value creation cannot be ignored. The value creation of a sustainable business model specifically describes how an enterprise creates value for its target customers, environment and society. It also describes how an enterprise realizes its economic, environmental and social value proposition in its actual production and operation activities. Value creation in the sustainable business model mainly includes the following three aspects: (1) how the enterprise's channel accesses the stakeholders at the environmental and social levels; (2) how the enterprise uses its core resources to create environmental and social value; (3) how the enterprise creates value for the environment and society through its key business.

A value network consists of many value chains formed among suppliers, enterprises, partners and customers. Nowadays, communities have become the heterogeneous resources of enterprises, and play a decisive role in product design. A clear positioning in the value network and a close relationship with partners in the network can enable enterprises to commercialize their products and technologies more quickly and surpass their competitors. A sustainable value network involves suppliers who are responsible not only for themselves but also for their core stakeholders. Enterprises need to think about and decide how to allocate resources and collaborate with each member in the value network to realize the value proposition, as well as decide which stakeholders are involved in the important cooperation of enterprises at the environmental and social levels and what values are created for them. In addition, enterprises should not transfer their own social and environmental burden to suppliers. This requires enterprises to effectively integrate suppliers into sustainable value network management.

The financial model on the economic level refers to how the enterprise obtains income and generates profit. The financial model can reflect the ability of enterprises to obtain value. A different financial model shows the difference in competitive strategy, system structure, resource allocation and internal ability construction, which ultimately determines the difference in economic performance. At the level of the environment and society, the main object of the financial model is no longer the enterprise but the environment and society. It refers to the positive and negative effects brought on by the actual production and operation of the enterprise on the environment and society. Only when the positive impact is greater than the negative impact can enterprises create positive environmental value and social value. On the one hand, a sustainable financial model should show the means and amount of consumers' payment, on the other hand, it should also show the way that the value created is distributed among consumers, enterprises, suppliers and even more stakeholders. This reflects the proper distribution of economic costs and benefits among all stakeholders involved in the business model.

Customer interface is a way for enterprises to contact with customers, and a process for enterprises to effectively transfer the value created to the target customers, and also is a continuation of the value creation process. The purpose of customer interface is to enable customers to purchase products or services, and to enhance customer experience in order to obtain more profits. The design of the customer interface will directly affect the image of the enterprise in the customer's mind, and also help the enterprise to obtain customer demand more directly. A sustainable customer interface means that enterprises should encourage customers' awareness of their own consumption responsibility. As the key role in the life-cycle management, customers should be encouraged to engage in green behaviors [69], such as green production and the recycling of products. Enterprises should also not 
pass on their social or environmental burdens to customers. In addition, due to the enhancement of consumers' green awareness, products and services based on environmental protection and social responsibility will also stimulate consumers' preference towards enterprises.

\subsection{Coupling Relationship of Dimensions}

Business model is not a single element, but a system of multiple elements. It is not the elements that determine the function of the system, but the relationships between them. When the elements are coupled, a virtuous circle of mutual reinforcement will be formed in the system. Business model starts from value proposition, acquires the stakeholder's value proposition by customer interface, obtains the external resources by value network to make up for the deficiency in the internal resources, and realizes value creation by a financial model through the operation of internal and external resources and capabilities. Value proposition is the key to the success of the business model, the starting point of all value activities of enterprises, and also shows the commitment of enterprises to providing products or services to customers. Value proposition should not only reflect the needs of customers, but also be recognized by partners. Value creation and value network are the process of establishing and coordinating the relationship between enterprises and business partners, transforming resources into value and transferring them to stakeholders. The financial model is the process or mechanism by which enterprises obtain a certain share of the total value created. It can be seen that the relationship between value proposition, value creation, value network, financial model and customer interface are not simple and linear, but are an interrelated, interactive and mutually promoting collaborative. As enterprises obtain a clear value proposition through customer interface, value creation and value network will be more efficient with a clear goal. In the same way, value creation and value network will also have an impact on the financial model of enterprises, because only when value is created can value acquisition and distribution be generated. In addition, in some cases, a clear financial model can make enterprises more effectively integrate the power of different stakeholders to create value, which is conducive to the construction and management of a value network. The five dimensions are interdependent and closely coupled, forming a complementary and collaborative integral whole. In that case, the function of the business model will be significantly improved, and the enterprise will have an overall and sustainable competitive advantage, rather than a temporary advantage based on a single point.

\section{Method}

\subsection{Research Design and Methods}

This study has adopted a case-based approach $[70,71]$. The main reasons for this are as follows: firstly, the case study is a useful method to explain "why" and "how". As Sun et al.'s research on how to build business model through simple rules shows [72], this paper focuses on how enterprises can realize the transformation of the sustainable business model based on a digital twin platform network, so it is suitable to adopt a case study. Secondly, considering that the creation process of the three benefits belongs to exploratory research, this paper chooses an exploratory case study method which is helpful to summarize and refine the general strategy behind the business phenomena.

Following the principle of sampling, the selected sample cases should meet the requirements of typicality, content adaptability, replicability [73] and data availability. In view of this, this paper chooses Haier as the case study object. The specific reasons for this are as follows: firstly, enterprise typicality-focusing on being user-centered, Haier Smart Home has experienced the development stage from a single product to a complete set of smart solutions, then to full-scene solution. It continuously leads the development of the industry through "extreme product experience", "strong platform capability" and "comprehensive landing capability". Second, content adaptability—against the background of digital economy, Haier has shifted to intellectualization in an all-round way. It leads in the fields of artificial intelligence, cloud computing, big data, and so on. At the same time, it subverts 
traditional thinking and builds an open entrepreneurial platform. Based on the advantages of global layout, brand and network, Haier provides users with the concept of life X.0, and their strategy in the IoT era brings convenience, health, safety and comfort to customers with one-stop, full-scene solutions. Third, replicability-Haier COSMOPlat is a cross-industry, cross-domain, cross-cultural replication platform with global universality. This means that it is not only applicable to the household appliances industry and manufacturing industry, but also can achieve cross-industry, cross-domain, cross-cultural comprehensive replication. All walks of life can enhance the competitiveness of the whole industrial process on COSMOPlat, and share its value for the users' life experience. Fourth, as a representative enterprise of the manufacturing industry, Haier, with its advanced management concept and strategy which are at the forefront of the industry, has abundant materials such as case study articles, external reports and books, which all conform to the data availability principle of the case study.

Based on the "evidence triangle or multi-angle" principle of the case study [74], this study seeks to collect case-related information as comprehensively as possible through feasible channels for theoretical research and problem exploration. Data were collected from multiple sources. The sources of first-hand information mainly include in-depth interviews, informal discussions, field visits, and informal conversations. For potential customers, some first-hand information can be obtained through the experience of the enterprise's official platform, physical stores, and anonymous interactions with the enterprise. Other first-hand data used in this case study come from the official website, annual report, prospectus, official Wechat public account, official microblog and other sources of enterprise information. The collected second-hand information includes news reports and literature journals related to Haier in authoritative databases (such as CNKI and Wanfang), and a large number of official publications.

\subsection{Overview of Haier}

Haier is the world's leading brand of major household appliances and is now transforming from a traditional manufacturer to an open entrepreneurship platform. Based on the "RenDanHeYi" model, it actively promotes the Internet transformation from the directions of strategy, management models, a research and development system, and a manufacturing system and service system.

On 1 July 2019, Qingdao Haier Co., Ltd. has officially changed its name to "Haier Smart Home Co., Ltd.". The change in name has released an important signal that Haier has entered into the Internet of things smart home ecology. It also demonstrates that Haier embraces the smart home, seizes the commanding point of the smart home market, and is realizing the creation of an ecological brand in the Internet of Things era with the smart home.

\subsubsection{Haier's Transformation Mechanism}

In March 2019, Haier launched the brand's first full-scene Smart Home Solution [75]. Haier smart home uses digital technologies, including the Internet of Things, artificial intelligence and big data. Through the Open Internet of Things platform $U^{+}$, it transforms traditional electrical appliances into smart appliances, provides users with a full-scene solution and connects an entire household into one system, as well as following the concept of $5+7+\mathrm{N}$ to achieve a new experience of the smart home. In the system, 5 represents the living scenarios of a smart living room, smart kitchen, smart bathroom, smart balcony and smart bedroom; 7 represents whole-house solutions for air, water, clothes care, security, voice control, health and information; and $\mathrm{N}$ is the variable that allows users to customize the smart home experience to best suit their needs.

The smart home is not a new concept. As early as 2014, Haier built the world's first smart life platform $U^{+}$, based on the technology and data support of $U^{+}$. The "netcraft" of Haier smart home solutions can realize self-perception, self-judgment, proactive decision-making and connectivity.

Haier's smart home exploration has experienced four stages of development: single-product smart stage, complete-set smart stage, scene smart stage and ecological smart stage. In the single product smart stage, Haier completed the transformation from electrical appliances to netcraft, allowing 
products to provide smart services and solutions through a network. In the complete set-smart stage, the netcrafts can connect with each other and actively provide smart life services. In the scene smart stage, Haier released a smart home composed of a whole set of interconnected smart appliances in 2017, involving 161 smart life scenes in different physical spaces such as the living room, kitchen, bathroom and bedroom. After that, they further released the ' $5+7+\mathrm{N}^{\prime}$ smart, full-scene, customized, full-set program, and quickly implemented it. In the ecological smart stage, smart home appliances not only satisfy users' basic needs, but also connect third-party resources to build an ecosystem of food, clothing, housing and entertainment, providing a constantly enriched and iterative ecological scene experience.

Externally, Haier built a smart home platform, through the exploration and practice of the business model of "netcraft + application + service + platform", to achieve an ecological scene experience; internally, COSMOPlat platform combined Haier's Interconnected factory model with the digitization and productization of knowledge to build an industrial Internet platform. It integrates Haier's existing functionalities, such as intelligent equipment, intelligent control, mold and research institutes, and has already collaborated with relevant companies in 15 industries, and offered comprehensive solutions and value-added services through the combination of software and hardware, as well as click-and-mortar for the enterprises' upgrading and smart manufacturing transformation.

Haier's original "RenDanHeYi" model has played a supporting role. 'Ren' refers to employees who have the spirit of entrepreneurship and innovation, 'Dan' refers to order, that is, the value of users, and "HeYi" means zero distance connection between employees and users. Each employee creates value for the users in a different self-employed business, thereby realizing their own value, and the corporate's value and the shareholder's value is naturally realized. In this model, employees compete for jobs, and their salary is determined by the user value they create. The mode of "RenDanHeYi" subverts enterprises from traditional, huge organizations to entrepreneurial platforms. The interconnection between entrepreneurial platforms breaks through the boundaries of the way organizations obtain resources, and the circulation of multi-factor resources within organizations optimizes the production costs of enterprises and creates greater synergy. Haier's "RenDanHeYi" mode changes the way of value creation and value acquisition. It not only realizes the change in production model and pays attention to the needs of personalized customization, but also creates the conditions needed for employees to realize their own value.

Haier has already established three major platforms in its smart home business- the smart home sector's first IoT platform $U^{+}$, the first IoT social app Shunguang, and the world's first industrial Internet platform COSMOPlat [76] (as shown in Figure 2). This has built up a robust foundation for its world-leading smart home network and brand portfolio, ensuring that Haier continues to deliver innovative smart home experiences and devices to users.

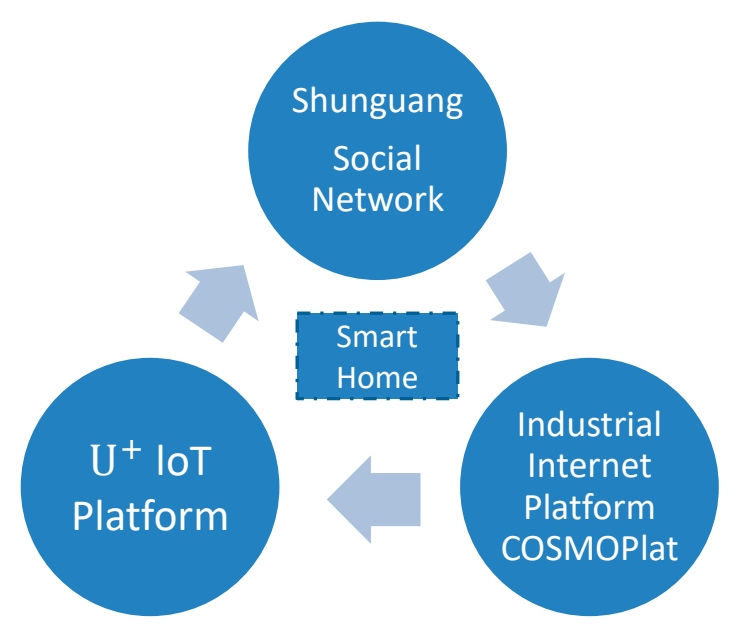

Figure 2. Haier Smart home platforms. 
Haier will manufacture its smart home appliances through COSMOPlat, the largest-scale customizable solution platform, which integrates global resources, cross-validates with users to achieve all-around interactive control of household appliances, customizes living scenarios, individualizes appliance functions intelligently and centralizes a family's information in one hub.

The upgrading of Haier household appliances includes not only the internal construction of interconnected factories to achieve the real-time interconnection of the personalized needs of consumers, but also the external construction of the $U^{+}$open platform of smart life, aiming at providing consumers with solutions for a smart life in an Internet age, so as to realize the best experience of interaction, transaction and delivery for consumers.

Haier also extends its networks to social networks and community economies while building the smart home networks, and continuously enhances the user value of Haier products and services, to provide interconnected smart home experiences and qualitied products globally.

In sum, based on the smart home, Haier has established a platform network of mutual connection and support. Among them are the Shunguang social platform, which functions as the user contact end, the COSMOPlat platform, which enables products, services and solutions to be implemented quickly, and the $U^{+}$platform, which gathers more developers and resources. The case study of this paper is mainly about how Haier's digital twin platform network, based on these three major platforms, can help enterprises to innovate the sustainable business model.

\subsubsection{Haier's Achievement in Economic, Social and Environmental Benefits}

As previously mentioned in the literature review, the research on the topic of sustainability concerns the implications of the digital transformation in terms of economic, environmental, and social benefits, referring to the triple bottom line (TBL) dimensions of a sustainable business model. Enterprises have to rely on a new business paradigm and have to directly or indirectly generate economic, social, and environmental benefits. Therefore, this paper takes the three benefits as the criterion for selecting Haier as the case study object of a sustainable business model. Since Haier started to build the smart home in 2014, it collects Haier's historical data of three benefits from 2014 to 2018.

\section{- $\quad$ Economic}

As the world's leading producer of major household appliances, Haier Group builds a global selling network comprised of 143,300 sales outlets spanning more than 160 countries. The following Figure 3 is a broken line chart of Haier's revenue growth from 2014 to 2018. As shown in Figure 3, Haier's global revenues in 2018 were 183.317 billion RMB, with a year-on-year growth of $15 \%$.

$\sim$ Operating revenue(Billion)

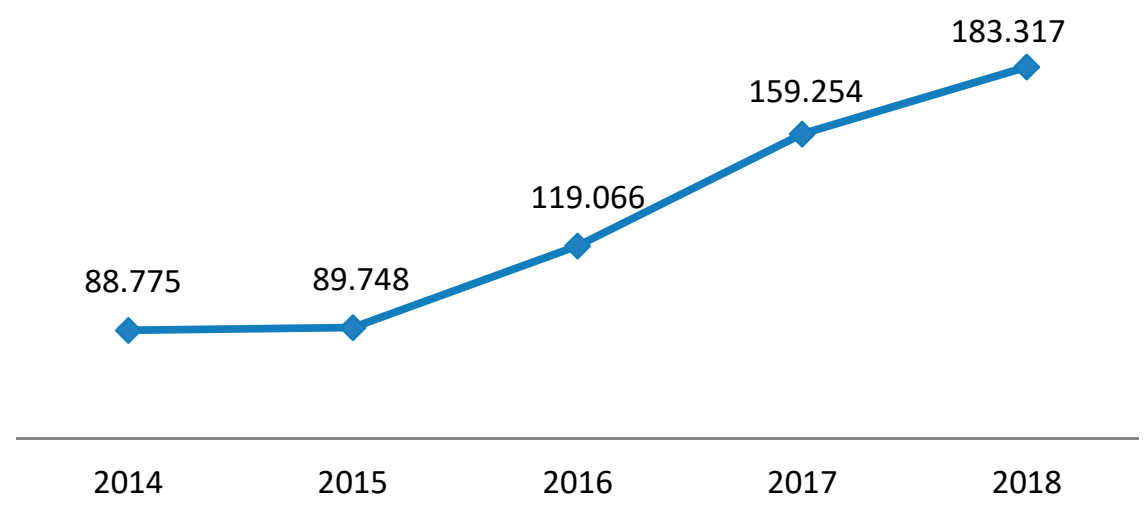

Figure 3. Haier's annual revenue.

- Environmental 
For a long time, Haier has invested in the improvement of the treatment capacity of pollutants discharged from production. It also focuses on reducing the consumption of non-renewable energy. In 2018, Haier deepened the implementation of the "green design, green manufacturing, green marketing, green recycling" $4 \mathrm{G}$ green strategy, which continued to promote environmental development and actively promote environmental consumption, achieving a $16.67 \%$ reduction in energy consumption per unit output value (As shown in Figure 4), which meant five consecutive years of decline, saving 16,787 tons of standard coal, and reducing carbon dioxide emissions by 44,221 tons. Moreover, the disposal rate of waste has reached $100 \%$.

$\sim$ Energy consumption per unit of output value(Kgce/Ten thousand yuan)

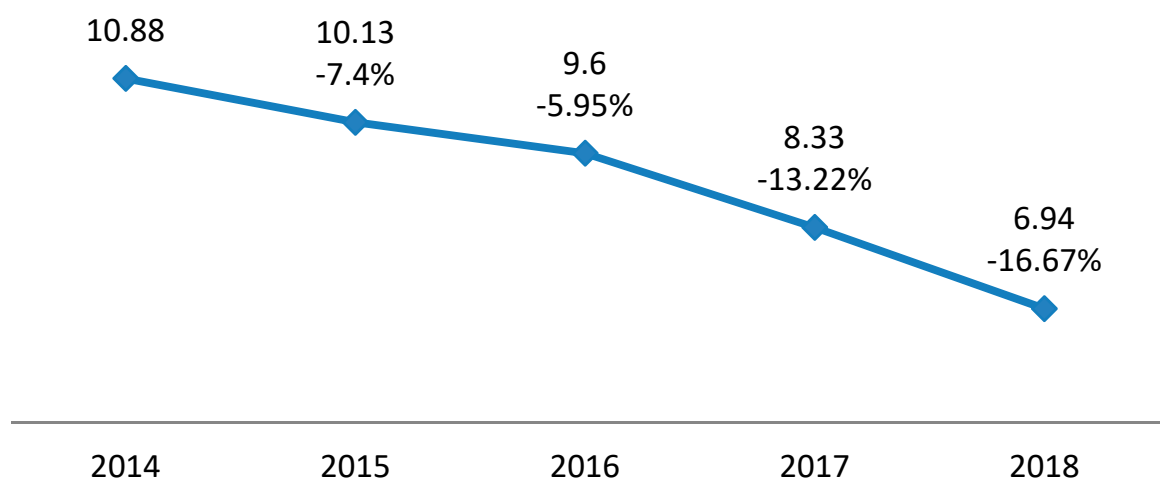

Figure 4. Haier's Energy consumption per unit of output value.

\section{- Social}

Haier has always believed in the unshakable responsibility of enterprises to actively fulfill social responsibility. Haier's social responsibility model includes nine types of stakeholders: government, consumers, employees, suppliers, distributors, shareholders, industry peers, social groups and the public. In the process of continuously improving the digital twin platform network, Haier has brought benefits to more stakeholders. Haier's original RenDanHeYi model has transformed employees into self-employed businesses, creating value for users and helping them to realize their own value. Moreover, Haier implements the intelligent HSE6S cloud platform system, and realizes the construction of a safety culture to ensure the personal safety of employees. It achieves a recordable injury rate of 0.07 per 200,000 working hours, which has continued to decline for two consecutive years, and fell by $46.58 \%$ in 2018. In addition, Haier promotes the integration of supply and demand from the perspective of user demand, and built an ecological user platform for the whole process of home appliance service. It subverts and reengineers the whole process of service, and creates a visual, digital and intelligent integrity service to bring users a faster, closer and more intelligent service experience. Haier's characteristic supplier management emphasizes sharing information between cooperative suppliers. Haier has realized more information exchanges with suppliers, and assisted suppliers in reducing costs, improving quality, speeding up the product development progress, and replacing short-term contracts with long-term trust cooperation, thus reducing transaction costs and management costs. For shareholders, Haier is committed to protecting the legitimate rights and interests of shareholders and actively returning investors through sustained and steady performance growth. At the same time, Haier actively participates in public welfare undertakings and vigorously supports education. Haier uses the Internet to build a public welfare ecosystem, linking scattered social resources with charity. The Shunguang platform builds a public welfare community network through community interaction, and publishes and displays public welfare projects on the platform. It not only presents information truthfully and transparently, but also facilitates the online interaction and participation of partners, users, fans, etc. Haier's exploration of public welfare model innovation 
provides more personalized platforms for people from all walks of life to participate in public welfare, which helps to improve the overall level of charity. The following are the historical indicators of Haier's social benefits, which are provided in Haier's Social Responsibility Report (as shown in Figure 5). Haier's social contribution value has continued to grow since 2015. In 2014, in order to further protect the interests of shareholders, Haier established a long-term mechanism of share repurchase, intending to use its own funds to repurchase the circulating A-shares through centralized bidding.

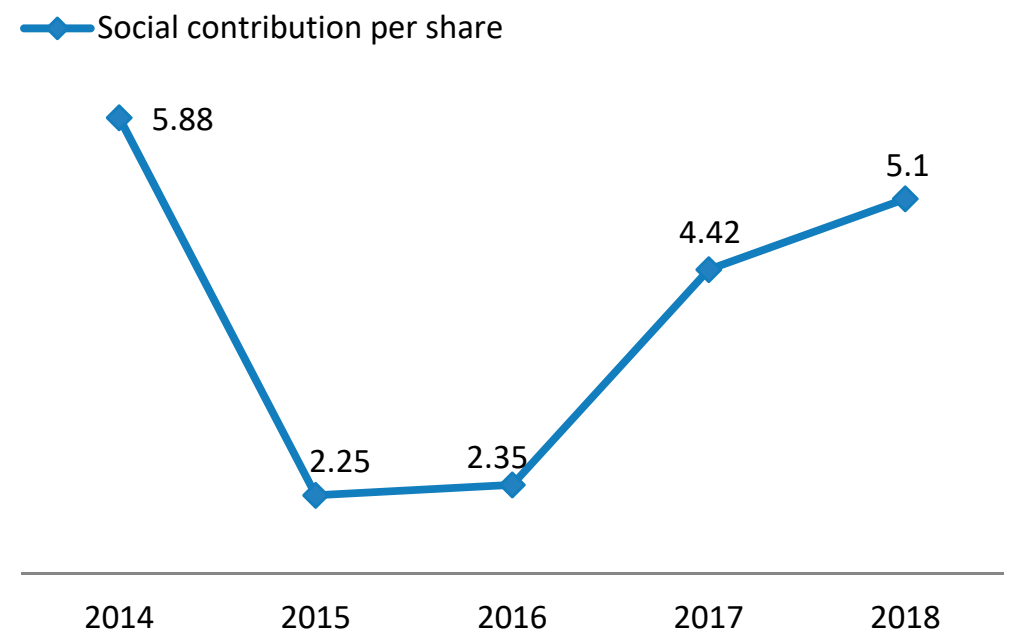

Figure 5. Haier's social contribution per share.

This calculation index is derived from the files of the Shanghai Stock Exchange. The calculation formula is: social contribution value per share $=$ earnings per share $+($ total tax payment + employee expenses + interest expense + total public welfare investment - social cost)/capitalization. Among them, the employee expenses include the cash paid to and for the employees.

\subsection{Case Study of Haier}

Digital twin can comprehensively improve the whole life cycle management of products by establishing the digital mapping of physical products and based on the data generated in the use of products, it can form closed-loop of feedback and optimization. It can get through different functional departments such as R\&D, supply chain, manufacturing, marketing, and even the ecosystem of enterprises. It can sense the needs of customers all the time and drive an efficient, interconnected and customer-centric operation model which can improve product experience, reduce cost and increase benefits.

Haier integrates all kinds of user information, product information, equipment information, logistics service information, technical resources, supplier resources and other information on a unified cloud platform, and integrates the technical resources of $R \& D$, procurement and other links in the upstream production process, so that users can interact with all smart products and the whole production process. Haier has built interconnected factories based on this cloud platform. The form of interconnected factory not only changes the dimensions of value creation but also the dimensions of the of value network. Through more efficient cross-border information sharing and resource allocation, enterprises can greatly improve the utilization rate of resources and reduce the waste of resources. On the one hand, Haier's interconnected factory realizes internal and external interconnection, and the interconnection between users, design and the production department. On the other hand, it realizes the interconnection of information between equipment and product. Operators can communicate with technical experts in remote real-time audio and video, while experts can give feedback information to the operator through virtual entities. Using digital twin to get through all the value links of the enterprise and establish the coupling relationship between the dimensions of the business model (as shown in Figure 6), to a certain extent. It can also strengthen the information communication of the 
enterprise and improve the resource allocation, thus contributing to the production of the economic and social environmental benefits of the enterprise.

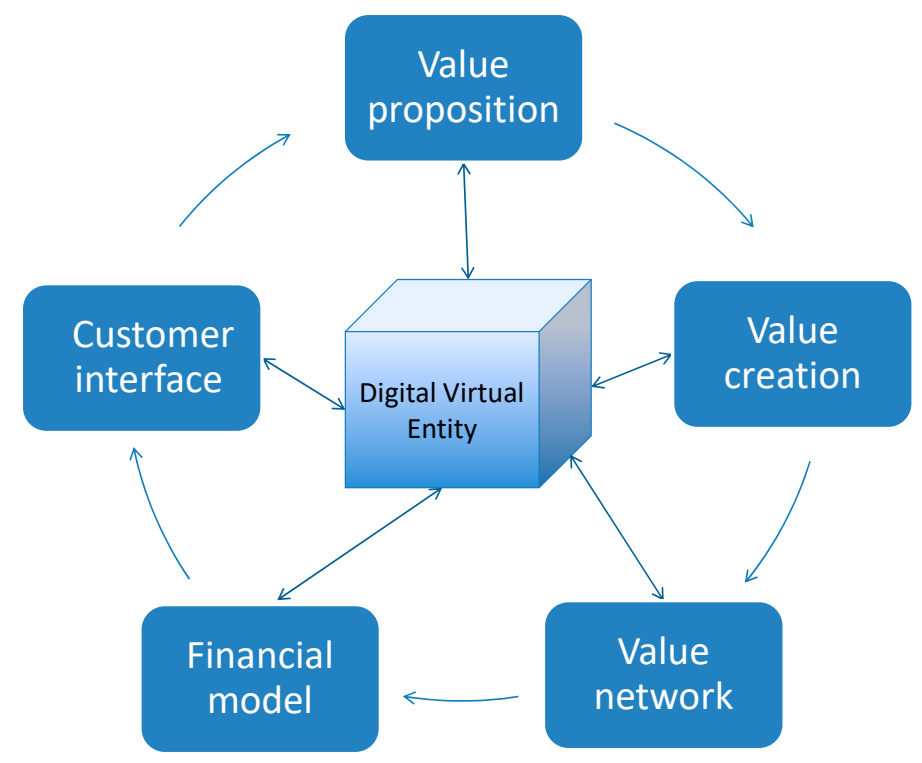

Figure 6. Five dimensions mapping in digital twin platform network.

Digital twin enables enterprises to turn products into a dynamic platform, continuously acquire customers' needs, take appropriate actions at the right time and in the right scene, provide customers with better products and services, and promote the disruptive upgrading of core processes and customer experience. Haier's smart appliances can intelligently adjust the life scene according to the user's habits, and can feed back the user's usage habits and usage information to the production device in real time, so as to use the information in the R\&D, design and procurement links.

Therefore, the next part will specifically analyze how Haier innovates the sustainable business model through the digital twin platform network from the perspective of the above-mentioned sustainable business model framework and the relationship between dimensions.

\subsubsection{Value Proposition}

Value proposition refers to the value embedded in the products and services provided by enterprises. When providing products and services, enterprises should not only include economic value, but also social value and environmental value, such as the consumption of resources and energy of products, and the actual value to users.

On one hand, Haier guides consumers to create environmental benefits by providing green products. Haier Maglev Central Air Conditioner has the advantages of 50\% energy saving, three-year maintenance, 2 ampere low current start-up, a 30 year service life, etc. It has greatly improved the green environmental protection demand of buildings, and continues to lead the green development of central air conditioning. Haier smart refrigerator reduces product deterioration through temperature control induction technology, prolongs shelf life, and consequently saves energy. There will be an automatic reminder before food materials expire, to ensure the quality and freshness of food but also to make the best use of food.

On the other hand, the Haier smart home makes use of the Internet of Things, AI and big data to turn traditional electrical appliances into smart appliances through $U^{+}$platform. Through scenario business combined with ecological services, Haier smart home provides users with a full-scene solution and connects an entire household into one system following the concept of $5+7+\mathrm{N}$ to achieve a new experience of the smart home. Users can enjoy seven whole-house solutions, such as air, security, 
water, washing and so on, in the five continuous iteration physical spaces of the kitchen and bedroom, so that users can enjoy customized life scenarios, and improve their experience.

\subsubsection{Value Creation}

Enterprises create value by utilizing resources and capabilities within the enterprise in a new and sustainable way, and focus on the transformation of production and management modes. Haier COSMOPlat platform is the industry's first independent research and development, independent innovative and intelligent manufacturing of the Chinese industrial Internet platform.

Firstly, the COSMOPlat platform can provide a platform for users to participate in the whole process of mass customization. Users can also view every manufacturing scene in real time. This enables global consumers to participate in the design and production of products in the whole process, successfully breaking through the thick wall between manufacturers and users. Through this platform, enterprises can accurately acquire users' needs, satisfy users' experience, change the traditional enterprise-centered model to the user-centered Internet model and realize collaboration with uses. COSMOPlat platform can greatly improve the efficiency of enterprises and meet the value of users.

Secondly, the COSMOPlat platform helps enterprises to become capable of all-factor interconnection and realize zero-distance interaction between users and enterprises, enterprises and resources. Through the internal and external all-factor interconnection, equipment data, industrial data and user data are linked together to form a resource system to interact and meet the user's demand. Timely information transmission and resource allocation help Haier save a lot of the unnecessary waste of resources.

Moreover, in 2018, Haier Smart Energy Center has been upgraded iteratively to become a customized platform for smart energy. With equipment, instruments and cloud computing as technical support, it dialyzes the production links of factories and builds the energy industry chain. The Haier Smart Energy Center, a leading energy data analysis system in the industry, has been set up. By means of automation, information technology and a centralized management model, it realizes centralized dynamic monitoring and the digital management of water, electricity, gas and other major sources of energy consumption, and the data have been collected automatically and accurately for $24 \mathrm{~h}$. At the same time, through the system algorithm module, it can predict and analyze energy consumption data, optimize energy scheduling, reduce energy consumption per unit, improve the operation performance of energy management, and truly realize low-carbon production.

\subsubsection{Value Network}

Smart ecosystems need advanced solutions which require support from open innovation systems. Haier's five R\&D centers in the United States, Europe, Japan, Australia and China form an innovation resource network spreading across the whole world. At the same time, the open online platform, Haier Open Partnership Ecosystem (HOPE), provides an environment for global users and resources to conduct zero-distance interaction and continuously create innovative solutions. Moreover, the COSMOPlat platform not only gathers millions of user resources, but also aggregates more than 3 million ecological resources, forming three bilateral markets. Through horizontal, vertical and end-to-end integration, it forms an open, collaborative and win-win new industry ecosystem.

Furthermore, Haier also exerts a considerable influence on its stakeholders, while generating social and environmental benefits in the whole supply chain. Take the Clothing Network of Haier (as shown in Figure 7), for example. Haier clothing network takes clothes as the medium, and absorbs relevant resources such as clothing enterprises, fitting mirror manufacturers, and clothing technology providers. It realizes the customization of exclusive clothing washing, care procedures and the whole process service from clothing purchase to wearing, and extends the technology of RFID to the whole industry chain of intelligent traceability and intelligent manufacturing. It makes full use of the upstream and downstream links of clothing network to meet the needs of intelligent clothing management for manufacturers, stores and other scenarios. For clothing manufacturers, RFID technology solves the 
efficiency problem of large quantities of clothes in and out of warehouse, brings several times greater efficiency improvement for each logistics identification link, greatly reduces the cost, and realizes the data sharing of the entire clothing supply chain. At the same time, with the help of the clothing network ecological digital management platform, stores can quickly obtain user feedback information, adjust marketing strategies according to users' personalized needs, and achieve mutual benefit.

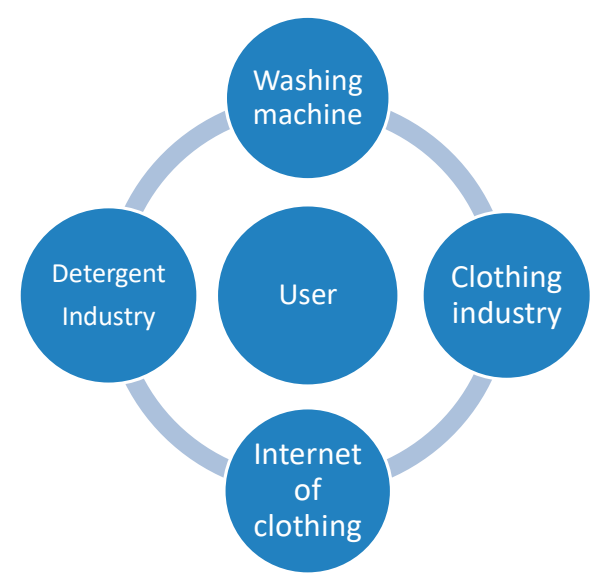

Figure 7. The Clothing Network.

\subsubsection{Customer Interface}

While many industry players focus on standard models, Haier is delivering consumers the possibility of customizing both products and solutions, as well as realize intelligent upgrades according to their actual habits and needs.

"User personalization" is a driving force of open innovation. In the age of Internet, it's getting easier and easier for users to get detailed product information. With the growth of Internet natives, user demands are getting more and more personalized and fragmental, and there is a growing requirement for customized products. Therefore, in order to meet user's personalized demands, enterprises have to change the traditional innovation method and co-create with users and first-class resources.

Based on $U^{+}$Cloud Brain and the knowledge atlas, Haier smart appliances can conduct deep learning, independent thinking and decision-making, and actively provide services for users. Take the smart water heater, for example. Using big data to collect and analyze information, using the $U^{+}$cloud brain deep learning model, the heating time and temperature of the water heater can be automatically adjusted. In addition, the data will be uploaded to the cloud. After calculation, water habits and energy-saving models will be established to further help machine learning and analysis of control operation strategies. Finally, through long-term machine learning, and according to the user's living habits, smart appliances can actively provide personalized customized solutions: the water will be heated when needed, the water temperature will be appropriate and will not cause the waste of water, so that users can receive a comfortable smart home experience.

Haier's innovative MFOP quality model has greatly improved product quality and reliability through the integration of the Internet of Things and the household appliances industry. Its advantages are mainly embodied by two aspects: first, through PHM core technology to pre-diagnose the functional status and service life of product components or systems, and in combination with users' needs, to provide users with product maintenance, remote maintenance and correcting problems beforehand. Secondly, the product comprehensively analyses the user's habits through big data, excavates the core points of demand, provides precise guidance for the further upgrading of products and services, and continuously iterates to provide the best user experience. 


\subsubsection{Financial Model}

The financial model reflects the appropriate distribution of benefits and costs among stakeholders involved in the whole value chain of business model. Enterprises should think about how to make use of consumers' awareness of social responsibility and environmental responsibility to transform their own environmental responsibility and social responsibility into consumers' demand. At the same time, enterprises should also consider the vulnerable groups in the value chain. Haier's "RenDanHeYi" model allows more capable employees to serve higher orders, create higher user value, forming a mechanism for sharing value between users and employees. The "RenDanHeYi" model gives employees more autonomy and stimulates their vitality. Employees become their own CEO, creating value for customers and realizing value for themselves at the same time. The original win-win mode of "RenDanHeYi" stimulates the internal motivation of employees, turns them into masters, and realizes their own value when creating value for users.

\subsubsection{Coupling Relationship of Five Dimensions}

Through the above analysis of the Haier smart home case, combining a digital twin platform network and sustainable business model, the paper draws a four-tier integrated framework, which are operation mechanism, digital twin platform network, a sustainable business model and a triple bottom line (as shown in the Figure 8).

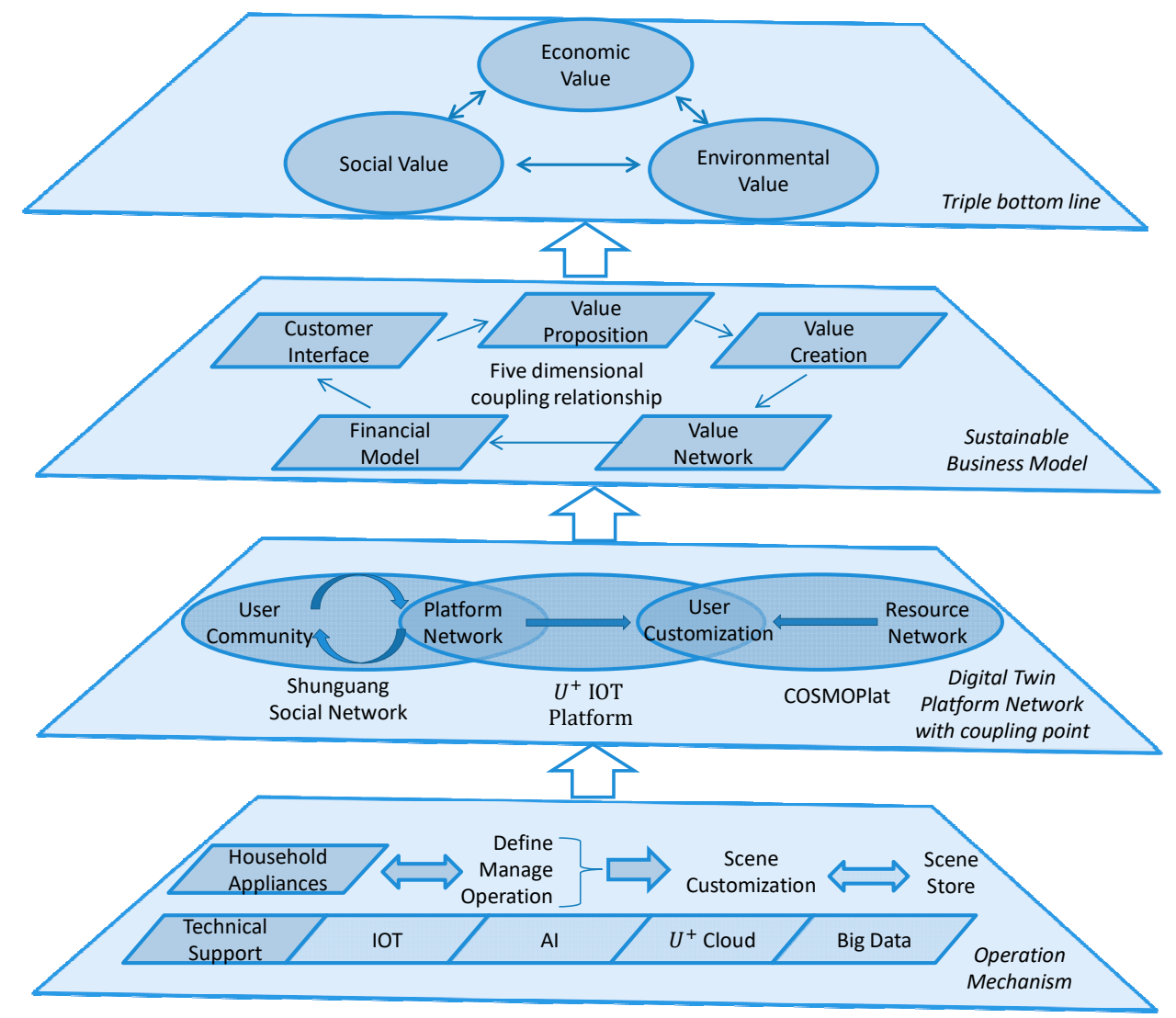

Figure 8. Integrated Framework of Haier smart home.

The Haier smart home can use the Internet of things, artificial intelligence and big data, through the $U^{+}$platform, turn traditional electrical appliances into smart network devices, and provide users with a full range of software and hardware solutions through scene store and the digital twin platform network, so as to achieve the best life experience for users. With the goal of leading smart homes in the era of Internet of things, Haier builds the $U^{+}$cloud, through natural human-computer interaction 
and distributed scene netcraft, it provides the industry with full-scene ecological solutions for the smart home. As shown in the operation mechanism layer, Haier takes smart household appliances as the entrance, and obtains user information and requirements with the Internet of things technology. Digital twin platform networks and netcrafts are used to define, manage and operate the life scene. Through interaction with the scene store, the $U^{+}$cloud could download scenes and give feedback, therefore the smart home appliance can provide users with customized service.

The Haier smart home is supported by three platforms, which are the Shunguang social network, $U^{+}$IOT platform and COSMOPlat platform. Among them, the Shunguang social platform works as the user contact end, the COSMOPlat platform enables products, services and solutions to be implemented quickly, while the $U^{+}$platform gathers more developers and resources. Combined with the third layer of sustainable business models, we can see the connection between Haier's platform network and the sustainable business model. The Shungang social network platform focuses on social interaction and subverts traditional e-commerce, aiming to build an Internet of things platform that integrates online stores, offline stores and micro stores and provides home solutions through personalized data. The Shungang platform becomes the entrance of the connection between users and enterprises, which changes the dimension of the customer interface. The $U^{+}$platform provides customized services for customers through smart appliances and cloud brain, which forms the development of Haier's value proposition.

Haier COSMOPlat has built 11 connected factories, connected by seven modules through the platform network, and enabled 15 industries, such as the Internet of food, the Internet of clothes, and the Internet of agriculture. The form of connected factory not only changes the dimension of value creation but also the dimension of the value network. Through more efficient cross-border information sharing and resource allocation, enterprises can greatly improve the utilization rate of resources and reduce the waste of resources, which is consistent with our concept of sustainability.

Furthermore, Haier's original "RenDanHeYi" model subverts the enterprise from the traditional organization to the entrepreneurial platform. The interconnection between the platforms breaks through the boundary of the enterprise's way of obtaining resources, and introduces the market mechanism into the traditional links of R\&D, production, manufacturing and sales. "RenDanHeYi" connects employees and users, as employees could realize their own value through creating value for users, and it also helps to maintain the stickiness of users. In this model, employees' compensation is determined by the user value they create. This is Haier's innovation in value creation and financial model.

Haier's three platforms are interconnected and mutually supportive, forming a sustainable platform network. As a user community, the Shunguang platform can help enterprises to collect users' value propositions and obtain users' needs. The user requirements will be summarized by the COSMOplat cloud platform. Under the mode of RenDanHeYi, the solution will be formed through employee competing, and then the partners in the platform will provide the corresponding resources. Finally, they will be delivered to the interconnected factory for production. During this period, users can see the whole production process. The coupling between platforms and the sharing of information resources saves a lot of manpower and material resources, and also generates new social and environmental benefits.

\subsection{Digital Platform Network Construction of Haier, Midea and Gree}

As the "three giants" of China's home appliance industry, Midea and Gree have also opened the road of digital transformation.

Midea's digital transformation adopts the strategy of "two intelligences", that is, smart home and intelligent manufacturing. Different from Haier's idea of user interaction and resource integration, Midea focuses on the automatic transformation of production lines to achieve the goal of efficiency improvement and scale customization. In the production line, Meida focuses on automation and information technology. Midea's intelligent manufacturing can not only improve the production efficiency, but also meet the user's one-to-one personalized customization needs. According to the 
construction of production lines in different workshops, Midea improves the interconnection and digital construction of each workshop by comprehensively using the core intelligent manufacturing equipment to transform the production line and improve the information network construction. Since 2011, Midea has established "632" strategy, namely six operation platforms, three management platforms, and two portals and integrated technology platforms. At present, Midea also actively wants to build a digital twin platform network and an industrial Internet. All business units comprehensively carry out industrial Internet reform, promote automation and intelligence, realize the digital operation of the whole value chain, drive management with data, and promote the continuous and in-depth digital transformation of businesses.

Gree mainly conducts independent research and development in the two directions of robot and precision machine tools, hoping to expand from the pure household appliance manufacturing industry to the new energy and equipment manufacturing industries. In addition, regarding the digital factory, it focuses on the interconnection between the manufacturing execution system and other systems, which can ensure that all relevant product information is kept synchronous from the beginning to the end, and realize real-time updates. Based on this, Gree has built a collaborative cloud (to create a standardized, transparent and dehumanized supply chain ecosystem, and to achieve the goal of opening up resources and reducing expenditure, improving efficiency management), Intelligent Cloud (to deliver accurately, improve efficiency and quality, reduce inventory, and make digital transparency), equipment cloud (to visualize equipment capacity, to maintain information, to prevent maintenance, to analyze abnormal closed-loop equipment, and to design full-state visualization) and smart human cloud (smart recruitment, smart access control, smart attendance, smart collaboration, smart cloud digitalization, visual application management) and other cloud platforms.

Haier's digital twin platform network mainly focuses on intelligent production and user ecology, aiming to get through the whole process node of interaction with users. Therefore, Haier has built the COSMOplat platform, which can realize the mass customization of products and improve the capacity of intelligent manufacturing around the needs of users. Unlike the other two enterprises, Haier has built a platform network to get through the whole process, making all dimensions coupled with each other, realizing the circulation of information in different functional departments, and improving the allocation efficiency of resources in various value links. Secondly, both Haier and Midea use digital twin technology to develop smart products and enhance user experience, which is helpful to increase social benefit. This is a point that Gree has not achieved at present. However, in terms of digital management, both Haier's RenDanHeYi model and Gree's smart human cloud have human management through the network platform. The construction of this platform can improve the financial model of enterprises, and realize the fair distribution of value among enterprises, employees and suppliers.

\section{Results}

\subsection{Generic Business Strategies}

This study contributes to the sustainable business model literature by providing insights into how enterprises use digital twin platform networks to generate economic, social and environmental benefits in various dimensions of the sustainable business model and the coupling relationship between them. Drawing on the case studies, we find that digital twin can be adopted in each dimension of the sustainable business model, and can generate economic, environmental and social benefits from various dimensions (specific strategies are shown in Table 1). The construction of a digital twin platform network integrates the information of each independent value link into a digital virtual entity, which helps to establish the coupling relationship among all dimensions. The improvement of resource utilization efficiency, and the optimization of user experience, reasonable financial allocation model, etc., can bring higher benefits to enterprises. The following is a detailed explanation of the generic business strategies in various aspects. 
Table 1. Generic Business Strategies.

\begin{tabular}{|c|c|}
\hline Dimensions of SBM & Generic Business Strategies \\
\hline \multirow{2}{*}{ Value Proposition } & Use digital technology to create smart/green products \\
\hline & Provide smart, customized services through real-time monitoring of the platform \\
\hline \multirow{2}{*}{ Value Creation } & Real-time production monitoring to allocate resources more effectively \\
\hline & Build a smart energy monitoring platform \\
\hline Value Network & Integrate the related enterprises in the supply chain into the information sharing platform \\
\hline \multirow{2}{*}{ Customer Interface } & Enable users to participate in product design and development through the platform network \\
\hline & $\begin{array}{l}\text { Use the digital twin platform network to predict, monitor, maintain and manage product and } \\
\text { improve user experience }\end{array}$ \\
\hline Financial Model & Use the platform to link the employees' salaries directly to users \\
\hline Coupling relationship & Use digital twin platform network to build information sharing among dimensions \\
\hline
\end{tabular}

In terms of value proposition, enterprises can make use of digital technology to create smart products to produce economic and environmental benefits, and, on the other hand, make use of a digital twin platform network to build a smart platform, improve user experience, provide customized services for users and improve social benefits.

From the perspective of value creation, enterprises can use the platform network to monitor the real-time manufacturing process, establish a resource allocation system through information sharing, and improves resource utilization efficiency. Secondly, it can be used to establish a customized platform for smart energy, predict and analyze energy consumption data, optimize energy scheduling, and reduce energy consumption per unit. Regarding the value network, the use of a platform network to integrate upstream and downstream enterprises in the supply chain into the information sharing system not only provides users with full-process services to improve user experience, but also helps upstream and downstream enterprises to more effectively manage and improve the utilization of resources. The customer interface dimension enables users to participate in product design and development through the platform network, and then use the digital twin platform network to predict, monitor, maintain and manage smart products and improve user experience. From the perspective of the financial model, enterprises can adopt models which link the employees' salaries directly to users to help employees gain more value and improve social benefits. Finally, in terms of the coupling relationship between dimensions, it can build different platforms, and establish the coupling between platforms, integrate the information of different links into a virtual entity, open the whole process, and effectively bring all stakeholders into the business activities of the enterprise, so as to improve social benefits. To a certain extent, the improvement in resource allocation ability among different departments will improve environmental benefits.

\subsection{Suggestions for Enterprise's Sustainable Transformation by Digital Technology}

Nowadays, the production mode of enterprises is gradually changing from mass production to small-batch and personalized manufacturing. The digital twin model of a product can reduce the time taken in the process of design and production, meet the needs of customer customization, and manage the whole life cycle of a product to improve the response speed to market demand, conducive to the growth of social and environmental benefits. Based on the above case analysis, this paper presents the following three suggestions on how to use digital twin to innovate the sustainable business model:

\section{- Intelligent manufacturing}

The combination of virtual and real information between physical products and digital twins can achieve a two-way closed-loop information feedback. Digital twin is not only a static digital model, but also can collect the operation data of physical products, and even control the physical products and change the state of products. Based on the digital twin platform network, enterprises can realize the intelligent upgrading of equipment, build intelligent production lines, and workshop decision-making systems and intelligent supply chains to ensure the efficiency and reliability of production system scheduling and management. It also enables users to participate in the whole production process 
in real time and improve production according to customer demand. Through the upgrading of intelligent manufacturing, enterprises can save resources, reduce pollution and improve environmental benefits, while customer participation in manufacturing process enhances customer experience, which is conducive to the growth of social benefits;

- Develop smart product and service

Digital twin enables enterprises to turn products into a dynamic platform, continuously acquire customers' needs, take appropriate actions at the right time and in the right scene, provide customers with better products and services, and promote the disruptive upgrading of core processes and customer experience. In addition, building digital twins can drill and integrate current, historical and decentralized business data, and provide support for different application scenarios. Through the digital twin platform network, smart products have a more friendly human-computer interface, but also have the function of "self-optimization", or automatically adjust according to user habits and use characteristics, which will bring consumers a better use experience. Smart products help enterprises to collect user habits, so that enterprises can more directly obtain customer needs, and can actively adjust to meet their needs, enhance user experience, and improve social benefits;

- Establish a platform network to link the whole process

Digital twin can comprehensively improve the whole life cycle management of products, get through different functional departments, constantly perceive the needs of customers, drive a customer-centric operation model, improve customer experience, reduce costs and increase efficiency. The implementation of digital twin also requires close collaboration between various departments. For example, through analysis of the data, it was found that a special design has little impact on product performance and customer experience, but the cost will affect the pricing and product reliability. At this time, R\&D department and supply chain department can balance the contradiction between the uniqueness of design and the cost of the supply chain. In addition, it is not enough to analyze and mine the value of the massive data collected by the digital twin only using the enterprise itself. The enterprise needs to share data with a third party, fully tap the value of the digital twin with the help of the external partners and promote the partners to participate in innovation. Therefore, the internal departments, users and external partners of the enterprise should work together to change the previous segmented process and split information state. The information process should realize a connection, turn the information into a synchronous ring state, focus on the users, feed back user needs to the enterprise operation, and allow all stakeholders to work together. The establishment of the whole process platform network is conducive to the communication of information between different departments, reduces the waste of resources caused by information asymmetry, and can bring all stakeholders into the production and operation of enterprises, which is conducive to the social benefits of enterprises.

\section{Discussion}

This paper contributes to the literature on the sustainable business model as follows. First, it deepens the understanding of the dimensions of the sustainable business mode and their coupling relationship. Previous studies of sustainable business models mainly focus on a single product life cycle or several dimensions of the business model. By studying a digital twin platform network, all aspects of the value chain and the coupling relationship between them are included in the scope of sustainable business model innovation. Secondly, it also enriches the study of sustainable business model innovation in a digital economy environment. Although many scholars have studied the construction of sustainable business model, there are few studies on sustainable business model in the digital economy environment. Third, this paper identifies how enterprises use the digital twin platform network to develop a sustainable business model. Through the detailed deconstruction of a 
case, it provides a reference for other enterprises to apply a digital twin platform network or digital technology to realize the innovation of sustainable business model.

This paper also carries certain limitations. It should be pointed out that this paper adopts the case study method. Although tracing a representative single case is beneficial to the theoretical construction, the representative case still has the particularity of the enterprise, which makes the study limited. Therefore, it is necessary for future research to expand the sample size, for example, consider industry differences, to further refine the viewpoints of this study through the principle of duplication, and improve the external validity of research. The case of this paper is based on the home appliance manufacturing industry. Various industries may have differences in digital technology and sustainable upgrading. Secondly, although this study explores the sustainable business model based on the digital twin platform network, the balance and transfer mechanisms of economic, environmental and social benefits within enterprises still need to be further explored. Finally, this paper adopts a qualitative method to explore the relationship between the digital twin platform network, and the coupling relationship between dimensions and three benefits. Future research can deepen the study by quantitative methods. For example, it could examine whether enterprises adopting digital technology have a higher performance in social, environmental and economic indicators.

\section{Conclusions}

This paper addresses how to use a digital twin platform network to generate economic, social and environmental benefits in various dimensions of sustainable business model and the coupling relationship between them. Based on the literature reviews, it puts forward a five-dimensional sustainable business model and explores the coupling relationship between them using an exploratory case study method, and taking Haier as an example to verify the five-dimensional framework and analyze the mechanism of Haier's innovation of sustainable business model based on the three major network platforms. This paper identifies the generic business strategies and provides references for enterprises to innovate the sustainable business model in the digital economy environment. Digitalization can reconfigure every aspect of enterprises' activities as multi-variety coordination and division of labor among enterprises will bring benefits under the condition of resource sharing. Enterprises need to adopt a systematic approach by drawing a digital roadmap to address business opportunities across their value chain. More importantly, enterprises should transform from enterprise-centered to user-centered. This can greatly improve the efficiency and effectiveness of enterprises and users' experience. Enterprises can learn from Haier to create a digital twin network to provide a comprehensive view of products, manufacture, supply chain, customer experience, service quality, performance and profitability. The findings of this paper enrich the study of sustainable business model innovation in the digital economy environment and also have implications for practice.

Author Contributions: X.L. (Xiao Li), Conceptualization, direction and review of the work; J.C., Writing-original draft, data collection; Z.L. and X.L. (Xinggang Luo), Editing of the paper. All authors have read and agreed to the published version of the manuscript.

Funding: This research was funded by Key projects of major Humanities and Social Sciences in Universities of Zhejiang Province (grant number 2016QN015), National Natural Science Foundation of China (grant number 71831006), and Natural Science Foundation of Zhejiang Province (grant number LY18G010008).

Acknowledgments: We would like to thank Haier for providing all the materials and information. We are grateful to the reviewers and editors.

Conflicts of Interest: The authors declare no conflict of interest.

\section{References}

1. Evans, S.; Vladimirova, D.; Holgado, M.; Van Fossen, K.; Yang, M.; Silva, E.A.; Barlow, C.Y. Business Model Innovation for Sustainability: Towards a Unified Perspective for Creation of Sustainable Business Models. Bus. Strat. Environ. 2017, 26, 597-608. [CrossRef] 
2. Wells, P. Sustainable business models and the automotive industry: A commentary. IIMB Manag. Rev. 2013, 25, 228-239. [CrossRef]

3. Dyllick, T.; Hockerts, K. Beyond the business case for corporate sustainability. Bus. Strategy Environ. 2010, 11, 130-141. [CrossRef]

4. Choi, J.; Wang, H. Stakeholder relations and the persistence of corporate financial performance. Strat. Manag. J. 2009, 30, 895-907. [CrossRef]

5. Porter, M.E.; Kramer, M.R. The big idea: Creating shared value. Harvard Bus Rev. 2011, 89, $2-17$.

6. Porter, M.E.; Kramer, M.R. The Competitive Advantage of Corporate Philanthropy. Harv. Bus Rev. 2003, 80, 56-68.

7. Geissdoerfer, M.; Vladimirova, D.; Evans, S. Sustainable business model innovation: A review. J. Clean. Prod. 2018, 198, 401-416. [CrossRef]

8. Chun, Y.-Y.; Lee, K.-M. Life Cycle-Based Generic Business Strategies for Sustainable Business Models. J. Sustain. Dev. 2013, 6, 8. [CrossRef]

9. Ceccagnoli, M.; Forman, C.; Huang, P.; Wu, D.J. Cocreation of Value in a Platform Ecosystem! The Case of Enterprise Software. MIS Q. 2012, 36, 263-290. [CrossRef]

10. Prahalad, C.; Ramaswamy, V. Co-creation experiences: The next practice in value creation. J. Interact. Mark. 2004, 18, 5-14. [CrossRef]

11. Parida, V.; Sjödin, D.; Reim, W. Reviewing Literature on Digitalization, Business Model Innovation, and Sustainable Industry: Past Achievements and Future Promises. Sustainability 2019, 11, 391. [CrossRef]

12. De, Q. Manufacturing: industry 4.0 and the digital twin. Softw. Integr. Circ. 2018, 406, 42-49.

13. Grieves, M.; Vickers, J. Digital Twin: Mitigating Unpredictable, Undesirable Emergent Behavior in Complex Systems in: Transdisciplinary Perspectives on Complex Systems; Springer: Cham, Switzerland, 2017. [CrossRef]

14. Kane, G.C.; Palmer, D.; Phillips, A.N.; Kiron, D.; Buckley, N. Aligning the Organization for Its Digital Future; MIT Sloan Management Review and Deloitte University Press: Cambridge, MA, USA, 2016; pp. 1-29.

15. Puthiyamadam, T. How The Meaning of Digital Transformation Has Evolved. Harvard Business Review. 2017. Available online: https://hbr.org/2017/05/how-the-meaning-of-digital-transformation-has-evolved (accessed on 10 September 2019).

16. Ji, L.; Li, H. Research on sustainable business model construction of food enterprises. Res. Bus. Eco. 2018, 4, $110-112$.

17. Du, S.; Xu, J.; Luo, Z.; Li, D.; Yu, X. Analysis of sustainable business model construction at the bottom of pyramid-A multi-case study based on northeast Guangdong. Manag. Rev. 2018, 30, 292-304.

18. Kondoh, S.; Kurakawa, K.; Kato, S.; Umeda, Y.; Takata, S. Analysis of key success factors for eco-business through case studies in Japan. Int. J. Autom. Technol. 2012. Available online: https://www.researchgate.net/publication/312653262_Analysis_of_key_success_factors_for_ecobusiness_through_case_studies_in_Japan (accessed on 3 August 2019).

19. Lovins, A.B.; Lovins, L.H.; Hawken, P. A Road Map for Natural Capitalism. Harvard Business Review on Profiting from Green Business. 2008. Available online: https://hbr.org/2007/07/a-road-map-for-naturalcapitalism (accessed on 3 August 2019).

20. Reinhardt, F.L. Bringing the environment down to earth. Harv. Bus. Rev. 1999, 77, 35-58.

21. Lee, R.P.; Spanjol, J.; Sun, S.L. Social Innovation in an Interconnected World: Introduction to the Special Issue. J. Prod. Innov. Manag. 2019, 36, 662-670. [CrossRef]

22. Hart, S.L.; Milstein, M.B. Creating sustainable value. Acad. Manag. Perspect. 2003, 17, 56-67. [CrossRef]

23. Bocken, N.; Short, S.; Rana, P.; Evans, S. A literature and practice review to develop sustainable business model archetypes. J. Clean. Prod. 2014, 65, 42-56. [CrossRef]

24. Zott, C.; Amit, R.; Massa, L. The Business Model: Recent Developments and Future Research. J. Manag. 2011, 37, 1019-1042.

25. Casadesus-Masanell, R.; Ricart, J.E. From Strategy to Business Models and onto Tactics. Long Range Plan. 2010, 43, 195-215. [CrossRef]

26. Yang, M.; Evans, S.; Vladimirova, D.; Rana, P. Value uncaptured perspective for sustainable business model innovation. J. Clean. Prod. 2017, 140, 1794-1804. [CrossRef]

27. Magretta, J. Why business models matter. Harv. Bus. Rev. 2002, 80, 86-133. [PubMed]

28. Doleski, O.D. The Integrated Business Model: An Applied Approach; Springer Science and Business Media LLC: New York, NY, USA, 2015; pp. 7-29. 
29. Battistella, C.; Cagnina, M.R.; Cicero, L.; Preghenella, N. Sustainable Business Models of SMEs: Challenges in Yacht Tourism Sector. Sustainability 2018, 10, 3437. [CrossRef]

30. Bansal, P.; Roth, K. Why Companies Go Green: A Model of Ecological Responsiveness. Acad. Manag. J. 2000, $43,717-736$.

31. Stubbs, W.; Cocklin, C. Conceptualizing a "Sustainability Business Model”. Organ. Environ. 2008, 21, $103-127$. [CrossRef]

32. Qu, Y.; Yu, Y.; Appolloni, A.; Li, M.; Liu, Y. Measuring Green Growth Efficiency for Chinese Manufacturing Industries. Sustainability 2017, 9, 637. [CrossRef]

33. Im, J.Y.; Sun, S. Profits and outreach to the poor: The institutional logics of microfinance institutions. Asia Pac. J. Manag. 2015, 32, 95-117. [CrossRef]

34. Boons, F.; Lüdeke-Freund, F. Business models for sustainable innovation: State-of-the-art and steps towards a research agenda. J. Clean. Prod. 2013, 45, 9-19. [CrossRef]

35. Schaltegger, S.; Freund, F.L.; Hansen, E.G. Business cases for sustainability: The role of business model innovation for corporate sustainability. Int. J. Innov. Sustain. Dev. 2012, 6, 95. [CrossRef]

36. Schaltegger, S.; Hansen, E.G.; Lüdeke-Freund, F. Business models for sustainability: Origins, present research, and future avenues. Organ. Environ. 2016, 29, 310. [CrossRef]

37. Schaltegger, S.; Lüdeke-Freund, F.; Hansen, E. Business models for sustainability: A co-evolutionary analysis of sustainable entrepreneurship, innovation, and transformation. Organ. Environ. 2016, 29, 264-289. [CrossRef]

38. Ekwueme, C.M.; Egbunike, C.F.; Onyali, C.I. Benefits of Triple Bottom Line Disclosures on Corporate Performance: An Explora-tory Study of Corporate Stakeholders. J. Manag. Sustain. 2013, 3, 79-91. [CrossRef]

39. Hussain, N.; Rigoni, U.; Orij, R.P. Corporate Governance and Sustainability Performance: Analysis of Triple Bottom Line Performance. J. Bus. Ethic. 2018, 149, 411-432. [CrossRef]

40. Matos, S.; Silvestre, B.S. Managing stakeholder relations when developing sustainable business models: The case of the Brazilian energy sector. J. Clean. Prod. 2013, 45, 61-73. [CrossRef]

41. Garbie, I.H. Sustainability Awareness in Industrial Organizations. Procedia Cirp 2015, 26, 64-69. [CrossRef]

42. Dembek, K.; York, J.; Singh, P.J. Creating value for multiple stakeholders: Sustainable business models at the Base of the Pyramid. J. Clean. Prod. 2018, 196, 1600-1612. [CrossRef]

43. Sosna, M.; Trevinyo-Rodríguez, R.N.; Velamuri, S.R. Business Model Innovation through Trial-and-Error Learning: The Naturhouse Case; Elsevier: Oxford, UK, 2010; Volume 43, pp. 383-407.

44. Abdelkafi, N.; Tauscher, K. Business models for sustainability from a system dynamics perspective. Organ. Environ. 2016, 29, 74-96. [CrossRef]

45. Joyce, A.; Paquin, R.L. The triple layered business model canvas: A tool to design more sustainable business models. J. Clean. Prod. 2016, 135, 1474-1486. [CrossRef]

46. Sun, S.L.; Zou, B. Generative Capability. IEEE J. Mag. 2018, 66, 1-14.

47. Morris, M.; Schindehutte, M.; Allen, J. The entrepreneur 's business model: toward a unified perspective. J. Bus. Res. 2005. [CrossRef]

48. Giesen, E.; Berman, S.J.; Bell, R.; Blitz, A. Three ways to successfully innovate your business model. Strat. Leadersh. 2007, 35, 27-33. [CrossRef]

49. Sorescu, A.; Frambach, R.T.; Singh, J.; Rangaswamy, A.; Bridges, C. Innovations in Retail Business Models. J. Retail. 2011, 87, S3-S16. [CrossRef]

50. Lenka, S.; Parida, V.; Wincent, J. Digitalization capabilities as enablers of value co-creation in servitizing firms. Psychol. Mark. 2017, 34, 92-100. [CrossRef]

51. Cheah, S.; Wang, S. Big data-driven business model innovation by traditional industries in the Chinese economy. J. Chin. Econ. Foreign Trade Stud. 2017, 10, 229-251. [CrossRef]

52. Bonilla, S.H.; Silva, H.R.O.; Da Silva, M.T.; Gonçalves, R.F.; Sacomano, J.B. Industry 4.0 and Sustainability Implications: A Scenario-Based Analysis of the Impacts and Challenges. Sustainability 2018, 10, 3740. [CrossRef]

53. Maffei, A.; Grahn, S.; Nuur, C. Characterization of the impact of digitalization on the adoption of sustainable business models in manufacturing. Procedia Cirp 2019, 81, 765-770. [CrossRef]

54. Savastano, M.; Amendola, C.; Bellini, F.; D’Ascenzo, F. Contextual Impacts on Industrial Processes Brought by the Digital Transformation of Manufacturing: A Systematic Review. Sustainability 2019, 11, 891. [CrossRef] 
55. Tao, F.; Cheng, J.; Qi, Q.; Zhang, M.; Zhang, H.; Sui, F. Digital twin-driven product design, manufacturing and service with big data. Int. J. Adv. Manuf. Tech. 2018, 94, 3563-3576. [CrossRef]

56. Söderberg, R.; Wärmefjord, K.; Carlson, J.S.; Lindkvist, L. Toward a Digital Twin for real-time geometry assurance in individualized production. Cirp Ann. 2017, 66, 137-140. [CrossRef]

57. Wang, L.; Törngren, M.; Onori, M. Current status and advancement of cyber-physical systems in manufacturing. J. Manuf. Syst. 2015, 37, 517-527. [CrossRef]

58. Liu, J.; Zhou, H.G.; Liu, X.J. Dynamic Evaluation Method of Machining Process Planning Based on the Digital Twin-based Process Model. IEEE Access 2019. Available online: https://ieeexplore.ieee.org/stamp/stamp.jsp? arnumber $=8631019$ (accessed on 3 January 2020).

59. Lim, K.Y.H.; Zheng, P.; Chen, C.-H. A state-of-the-art survey of Digital Twin: techniques, engineering product lifecycle management and business innovation perspectives. J. Intell. Manuf. 2019, 1-25. [CrossRef]

60. Vrabič, R.; Erkoyuncu, J.A.; Butala, P.; Roy, R. Digital twins: Understanding the added value of integrated models for through-life engineering services. Procedia Manuf. 2018, 16, 139-146. [CrossRef]

61. Cenamor, J.; Sjödin, D.R.; Parida, V. Adopting a platform approach in servitization: Leveraging the value of digitalization. Int. J. Prod. Econ. 2017, 192, 54-65. [CrossRef]

62. Eloranta, V.; Orkoneva, L.; Hakanen, E.; Turunen, T. Using Platforms to Pursue Strategic Opportunities in Service-Driven Manufacturing. Serv. Sci. 2016, 8, 344-357. [CrossRef]

63. Eloranta, V.; Turunen, T. Platforms in service-driven manufacturing: Leveraging complexity by connecting, sharing, and integrating. Ind. Mark. Manag. 2016, 55, 178-186. [CrossRef]

64. Mont, O.K. Clarifying the concept of product-service system. J. Clean. Prod. 2002, 10, 237-245. [CrossRef]

65. Svensson, G.; Wagner, B. Transformative Business Sustainability: Multi-layer Model and Network of E-footprint Sources. Eur. Bus. Rev. 2011, 23, 334-352. [CrossRef]

66. Bocken, N.; Boons, F.; Baldassarre, B. Sustainable business model experimentation by understanding ecologies of business models. J. Clean. Prod. 2019, 208, 1498-1512. [CrossRef]

67. Teece, D.J. Explicating dynamic capabilities: the nature and microfoundations of (sustainable) enterprise performance. Strat. Manag. J. 2007, 28, 1319-1350. [CrossRef]

68. Richardson, J. The business model: an integrative framework for strategy execution. Strat. Chang. 2008, 17, 133-144. [CrossRef]

69. Nduneseokwu, C.K.; Qu, Y.; Appolloni, A. Factors Influencing Consumers' Intentions to Participate in a Formal E-Waste Collection System: A Case Study of Onitsha, Nigeria. Sustainability 2017, 9, 881. [CrossRef]

70. Yin, R.K. Case study research design and methods. J. Adv. 1989, 44, 108.

71. Yin, R.K. Applications of case study research. BMS 1993, 34, 101.

72. Sun, S.L.; Xiao, J.; Zhang, Y.; Zhao, X. Building business models through simple rules. Multinatl. Bus. Rev. 2018, 26, 361-378. [CrossRef]

73. Eisenhardt, K.M.; Graebner, M.E. Theory Building from Cases: Opportunities and Challenges. Acad. Manag. J. 2007, 50, 25-32. [CrossRef]

74. Schwandt, T.A. Qualitative data analysis: An expanded sourcebook. Eval. Prog. Plan. 1996, 19, $106-107$. [CrossRef]

75. Haier Smart Home. Available online: https://www.haier.com/smarthome/gyzhjt.shtml (accessed on 30 October 2019).

76. Lv, W. Intelligent manufacturing and global value chain upgrading-A case study of Haier COSMOPlat. Sci. Res. Manag. 2019, 40, 145-156.

(C) 2020 by the authors. Licensee MDPI, Basel, Switzerland. This article is an open access article distributed under the terms and conditions of the Creative Commons Attribution (CC BY) license (http://creativecommons.org/licenses/by/4.0/). 